\title{
A study on the relationship between resilience and forgiveness
}

\author{
Pooja Soni ${ }^{1}$ \\ ${ }^{1}$ Assistant Professor, Department of Psychology, K.C. College, Churchgate, Mumbai. \\ E-mail-poojajosh@gmail.com
}

\begin{abstract}
Background : We are living in a world grappled with issues of terrorist attacks, racial discrimination, manmade or natural disasters, hunger, poverty and many more. Can forgiveness be the answer to build resilience to deal with such adversities? Forgiveness means a conscious decision to release the feelings of resentment and vengeance towards the offender. Resilience is the process of adapting well in the face of adversity, stress, trauma or sources of significant stress. Many studies have shown that primary factor in influencing Resilience is- having caring and supportive relationships.

Methodology : The purpose of the study was to explore relationship between forgiveness and resilience. 95 undergraduate female college students participated in the survey. Students were given self report questionnaires that included Wagnild and Young's Resilience Scale, and the Heartland Forgiveness Scale. The Pearson's product moment correlation was done to find out the association between the two variables. Results : The results indicated a significant relationship between self-forgiveness and resilience $(p<0.01)$, forgiving others and resilience $(p<0.01)$, forgiveness of situations and resilience $(p<0.05)$ and overall forgiveness with resilience $(\mathrm{p}<0.05)$.

Conclusions : There is definite relationship between resilience and forgiveness as well as self forgiveness. These results may be applied in creating modules for personal counseling and couples therapy to build resilience through inculcating trait forgiveness.
\end{abstract}

Keywords: resilience, forgiveness, self-forgiveness.

\section{INTRODUCTION}

Youth today are faced with myriad of adverse experiences that can challenge their chances for life success and satisfaction, as well as negatively influence their perception towards life, the world, and themselves. College students, especially in their first year, are exposed to new social norms and customs, different peer groups, work overload, a change in lifestyle, as well as more demands placed on their time and their self-control [1-2]. However, sometimes, when certain youth show such resilience that they are able to grow above the obstacles in their environments and succeed as healthy, contributing members of their communities. Resilience is one of the foundations of well-being. Resilience generally refers to human's ability to bounce back in the face of serious adversities of life. It's a widely spread human ability that many people possess but not know until they come across any trauma or crisis [3]. Ryff and Singer define resilience as "maintenance, recovery, or improvement in mental or physical health following challenge" [4]. In addition to bouncing back from stress, resilience has also been defined as the ability to maintain a stable equilibrium in the face of stress [5], the ability to recover strength, spirits, good, humour quickly [6], function above the norm in spite of stress [7], adapt positively to adversity [8], balance internal needs and desires with the external environment [9] and a positive change that can emerge from the experience of trauma [10]. 
Resilient individuals bounce back from stressful experiences more quickly and effectively than others. Such people use humour, positive emotions, replacing negative thoughts with positive ones, social support, and optimism to cope with adversity [11]. Masten and Obradovic have delineated a set of factors which are frequently related with resilience across diverse situations. Factors supporting resilience are: cognitive skills (problem solving, information processing), attachment (close relationships with friends, caregivers), mastery motivation (self-efficacy), stress response, self-regulation (emotion regulation, executive functioning), family (parenting, interpersonal dynamics), school, peers (friendships, peer groups), and cultural and societal systems (religion, traditions, rituals, values, standards, laws) [12].

It's very difficult to identify a single, comprehensive and widely accepted definition of forgiveness. May be because the contexts in which forgiveness occur varies significantly. Forgiveness may involve oneself, others, God, families or society. Most researchers agree that forgiveness should be conceptualized as multidimensional involving dimensions of affect, cognition and behaviour. According to Enright, Forgiveness is a 20 steps process of replacing negative thinking, action and affect with positive ones [13]. In the theory espoused by Thompson and her colleagues, forgiveness is a freeing from a negative attachment to the source that has transgressed against a person. Of all forgiveness theories, Thompson's is the most inclusive in that the source of any eventual forgiveness may be oneself, another person, or a situation that is viewed as out of one's control [14]. According to McCullogh and his colleagues, forgiveness is defined as a redirection in negative motivations along with increase in pro-social motivation toward another in an interpersonal context [15]. Researchers have suggested that forgiveness reflected cognitive-affective transformation following a transgression in which the victim freely chooses not to take any revenge and makes a realistic assessment of the harm done [16]. Fincham and Kashdan argued that "at the center of various approaches to forgiveness is the idea of a freely chosen motivational transformation in which the desire to seek revenge and to avoid contact with the transgressor is lessened" [17]. Trait forgiveness involves a tendency to offer, feel, or seek changes from negative to positive cognitions, behaviours, and affect pertaining to offenders that include oneself, others, and God. Whereas State forgiveness involves a process of offering, feeling, or seeking a change from negative to positive cognitions, behaviours, and affect pertaining to specific offenses that are perceived to be perpetrated by oneself, others, or God [18].

\section{METHODOLOGY}

The present research is a preliminary research intending to examine relationship between resilience and forgiveness among female college students. The participants were 95 undergraduate female psychology students studying in first year $(n=67)$ and second year of Arts $(n=28)$ from a south Mumbai college (Age range $=17-20$ years). Questionnaires were administered after obtaining the informed consent.

The measures used in the study were -

- The Heartland Forgiveness Scale (HFS) : This is an 18-item dispositional measure that assesses forgiveness in three areas: forgiveness of self (e.g., "Although I feel bad at first when I mess up, over time I can give myself some slack"), others (e.g., "With time I am understanding of others for the mistakes they've made"), and situations (e.g., "Eventually I let go of negative thoughts about bad circumstances that are beyond anyone's control"). One's score on the Total Heartland Forgiveness Scale indicates how forgiving a person tends to be of oneself, other people, and uncontrollable situations. Higher scores indicate higher levels of forgiveness, and lower scores indicate lower levels of forgiveness. A score of 18 to 54 means that one is usually unforgiving of oneself, others, and uncontrollable situations. A score of 55 to 89 means that one is about as likely to forgive, as one is not to forgive oneself, others, and uncontrollable situations. A score of 90 to 126 means that one is usually forgiving of oneself, others, and uncontrollable situations. Concurrent validity for the scale has been demonstrated (Thompson et al., 2005). The scale also has adequate internal consistency, with alpha coefficients for the subscales ranging from 0.72 to $0.82[18]$. 
- Wagnild and Young's Resilience Scale (RS) : It has 25 items. All items are scored on a 7 point rating scale from 1- disagree to 7- agree. All items are worded positively and possible scores range from 25 to 175 with higher scores reflecting higher resilience. The internal consistency of RS ranges from 0.76 to 0.91 . Test - Retest reliability coefficients ranged between 0.67 to 0.84 which are respectable and suggest that resilience is stable over time. RS highly correlated with well established valid constructs like depression, life satisfaction, morale and health showing adequate concurrent validity [19].

A Pearson Product Moment Correlation was calculated to find out the relationship between resilience and forgiveness.

\section{RESULTS}

As can be seen in Table 1, the Mean score of the group on the resilience scale was $129.67(\mathrm{SD}=15.83)$ and on total forgiveness scale was $85.39(\mathrm{SD}=14.50)$. The mean of self forgiveness subscale was 28.97 ( $\mathrm{SD}=5.84$ ), of forgiving others sub-scale was $28.49(\mathrm{SD}=6.38)$ and of forgiving situations sub-scale was $27.93(\mathrm{SD}=6.53)$. This showed that participants in the group were in between that is as likely to forgive as not likely of themselves, of others, of situations as well as overall on an average. The obtained range of scores on both the scales and subscales were lower than the possible range. The SDs also indicated that there were less individual differences in participants.

The correlation between resilience and forgiveness was found out to be positive and low but statistically significant, $r(94)=0.28, p<0.01$. This indicated that as forgiveness increases, the resilience increases somewhat or vice versa. The correlation between self-forgiveness and resilience was $r$ $(94)=0.27, \mathrm{p}<0.01$, between forgiving others and resilience was $\mathrm{r}(94)=0.19, \mathrm{p}<0.05$ and between forgiving situations and resilience was $\mathrm{r}(94)=0.19, \mathrm{P}<0.05$. All these three correlations were positive and low but statistically significant. This demonstrated that as self forgiveness, or forgiving others or forgiving situations increase even the resilience increases somewhat. However, the low correlation might indicate that there are other factors also apart from forgiveness that can influence resilience.

Table 1 - Scores on various scales used in the study

\begin{tabular}{|cccc|}
\hline Variable & Range & Mean & S.D. \\
\hline Resilience & $72-169$ & 129.67 & 15.83 \\
\hline Forgiveness & $53-122$ & 85.39 & 14.50 \\
\hline $\begin{array}{c}\text { Self Forgiveness } \\
\text { subscale }\end{array}$ & $18-42$ & 28.97 & 5.84 \\
\hline $\begin{array}{c}\text { Forgiving Others } \\
\text { subscale }\end{array}$ & $10-46$ & 28.49 & 6.38 \\
\hline $\begin{array}{c}\text { Forgiving Situations } \\
\text { subscale }\end{array}$ & $13-42$ & 27.93 & 6.53 \\
\hline
\end{tabular}

\section{DISCUSSION}

A study was done on clinicians to explore the common definition of forgiveness. The experienced clinicians who responded to this study identified forgiveness as "an inner process, central to psychotherapy, where the injured person without the request of the other releases those negative feelings and no longer seeks to return hurt, and this process has physical, psychological, and emotional benefits." The only limitation of this definition was that this definition was the product of clinicians who were favourable to using forgiveness as a psychotherapeutic tool in therapy [20]. Several studies that have compared the mental health of people who have a natural propensity to forgive (trait forgiveness) with those who are not so inclined have shown that trait forgiveness has several mental health benefits like increasing well being, happiness, and life 
satisfaction [21]. A study assessed the effect of forgiveness and gratitude on life satisfaction and subjective well-being among Filipino college students. The statistical analyses of the data showed that gratitude served as the most prominent determinant of well-being after controlling demographic characteristics and forgiveness dimensions. Gratitude and forgiveness predicted subjective well-being, predominantly even beyond the influence of the big five personality factors [22].

Self-efficacy, hope and coping have emerged as defining features of resilience [23]. Higher self -efficacy have been associated with greater levels of persistence and resilience when faced with adversity. Hope also is shown to have been connected to reducing effects of stress on health and thus building resilience. Coping too has been thought to be a characteristic attribute of resilience as it determines a person's ability to objectively evaluate a situation so that adjustment can occur [24]. Researchers investigated the relationship between forgiveness and resilience among older adults. The analyses indicated a low, but statistically significant correlation between resilience and forgiveness $(r=0.339, p<0.05)$; as forgiveness increased, resilience tended to increase somewhat. Age was not found to be significantly associated with either resilience or forgiveness in bivariate correlations, but did prove significant when in combination with other variables [25]. When others investigated the relationships among resilience, forgiveness and anger expression, the data indicated that total resiliency significantly correlated with total forgiveness as well as total anger. Further analyses indicated that there are certain commonalities between resilience and forgiveness that can affect how adolescent express anger. This can further be applied to design interventions to incorporate forgiveness skills for school guidance programs for adolescents [26].

The limitations of the study were that the group was homogeneous; a larger sample would have allowed more heterogeneity. There were only girls participating in the study. Inclusion of boys would have added on other gender perspectives too. A larger and more representative sample can be used for further studies to find out the links between forgiveness and resilience. The author wishes to design a comparative study between a military sample and normal population to find out significant differences in resilience and forgiveness. The study has implications in the area of counseling where counselors can teach clients to forgive self, others and situation to build resilience and to cope with life changing situations and stressful conditions.

\section{REFERENCES}

1. Singh A. Upadhyay A. Age and sex differences in academic stress among college students. Soc Sci Int 2008;24:78-88.

2. Guo Y, Wang S, Johnson V, Diaz M. College students' stress under current economic downturn. Coll Stud J 2011;45(3):536-43.

3. Jackson D, Firtko A, Edenborough M. Personal resilience as a strategy for surviving and thriving in the face of workplace adversity: a literature review. J Adv Nurs 2007;60(1):1-9.

4. Ryff CD, Singer B. Flourishing under fire: Resilience as a prototype of challenged thriving. Flourishing: Positive psychology and the life well-lived 2003;15-36.

5. Bonanno GA. Loss, trauma, and human resilience: have we underestimated the human capacity to thrive after extremely aversive events?. Amer Psychol 2004;59(1):20-8.

6. Smith BW, Tooley EM, Christopher PJ, Kay VS. Resilience as the ability to bounce back from stress: A neglected personal resource?. J Positive Psychol 2010;5(3):166-76.

7. Tusaie K, Dyer J. Resilience: A historical review of the construct. Holist Nurs Pract 2004;18(1):3-10.

8. Luthar SS, Cicchetti D, Becker B. The construct of resilience: A critical evaluation and guidelines for future work. Child Dev 2000;71(3):543-62.

9. Block J, Kremen AM. IQ and ego-resiliency: conceptual and empirical connections and separateness. J Personal Soc Psychol 1996;70(2):349-61.

10. Levine SZ, Laufer A, Stein E, Hamama-Raz Y, Solomon Z. Examining the relationship between resilience and posttraumatic growth. J Traum Stress 2009;22(4):282-6.

11. Southwick SM, Vythilingam M, Charney DS. The psychobiology of depression and resilience to stress: implications for prevention and treatment. Annu Rev Clin Psychol 2005;1:255-91.

12. Masten AS. Ordinary magic: Resilience processes in development. Amer Psychologist 2001;56(3):227-38. 
13. Enright RD, Fitzgibbons RP. Helping clients forgive: An empirical guide for resolving anger and restoring hope. American Psychological Association; 2000.

14. Thompson LY, Snyder CR, Hoffman L, Michael ST, Rasmussen HN, Billings LS, Heinze L, Neufeld JE, Shorey HS, Roberts JC, Roberts DE. Dispositional forgiveness of self, others, and situations. J Personality 2005;73(2):313-60.

15. McCullough ME, Pargament KI, Thoresen CE, editors. Forgiveness: Theory, research, and practice. Guilford Press; 2001.

16. Tangney J, Fee R, Reinsmith C, Boone AL, Lee N. Assessing individual differences in the propensity to forgive. Presented in the Annual meeting of the American Psychological Association, Boston ; 1999.

17. Breen WE, Kashdan TB, Lenser ML, Fincham FD. Gratitude and forgiveness: Convergence and divergence on self-report and informant ratings. Personal Individ Diff 2010;49(8):932-7

18. Thompson LY, Snyder CR, Hoffman L. Heartland forgiveness scale. Kansas ; 2005.

19. Wagnild G. A review of the Resilience Scale. J Nurs Measurement 2009;17(2):105-13.

20. Denton RT, Martin MW. Defining forgiveness: An empirical exploration of process and role. Am J Fam Ther 1998;26(4):281-92.

21. Allemand M, Amberg I, Zimprich D, Fincham FD. The role of trait forgiveness and relationship satisfaction in episodic forgiveness. J Soc Clin Psychol 2007;26(2):199-217.

22. Datu JA. Forgiveness, gratitude and subjective well-being among Filipino adolescents. Int J Advance Couns 2014;36(3):262-73.

23. Gillespie BM, Chaboyer W, Wallis M. Development of a theoretically derived model of resilience through concept analysis. Contemporary Nurse 2007;25(1-2):124-35.

24. Worthington EL, Scherer M. Forgiveness is an emotion-focused coping strategy that can reduce health risks and promote health resilience: Theory, review, and hypotheses. Psychol Health 2004;19(3):385-405.

25. Broyles LC. Resilience: Its relationships to forgiveness in older adults [dissertation]. Knoxville, TN: University of Tennessee ; 2005.

26. Anderson KM, Danis FS. Adult daughters of battered women resistance and resilience in the face of danger. Affilia 2006;21(4):419-32.

$$
\begin{gathered}
\text { Acknowledgements - Nil. } \\
\text { Source of Funding - Nil } \\
\text { Conflict of Interest - Nil }
\end{gathered}
$$

